doi: 10.1897/1551-3793(2006)2[13:AOPABI]2.0.CO;2

\title{
Assessment of Persistency and Bioaccumulation in Pesticide Registration Frameworks within the Organization for Economic Cooperation and Development
}

\author{
Mark HMM Montforts ${ }^{1, *}$
}

1. National Institute for Public Health and the Environment (RIVM), Antonie van Leeuwenhoeklaan 9, PO Box 1, NL-3720BA, Bilthoven, The Netherlands

\begin{abstract}
This article describes the results of a survey conducted in 2003 on methods used by different member countries within the Organization for Economic Cooperation and Development (OECD) to evaluate persistent and bioaccumulative pesticides. The objectives were to establish the differences in taking persistence $(P)$ and bioaccumulation (B) into account in the decisionmaking process and to establish the influence of the assessors' subjectivity to data interpretation and data selection. Fifteen countries participated in the survey, which generated a vast amount of information on decision making, risk assessment, risk classification, and data treatment. Survey results indicated clear differences in approaches to the use of $P, B$, and toxicity $(T)$ information in scientific risk assessment. Using the same data for 2 different pesticides, several OECD member countries responded differently in classifying both substances as $P$, $B$, and $T$. Differences in regulatory decision-making were also apparent because, based on identical classifications, several OECD member countries adopted different decisions on pesticide registration; recommendations were based, with respect to technical guidance, on data handling, training of assessors, and handling of uncertainty in risk assessment.
\end{abstract}

Additional supporting data are found in appendices available on the online edition of IEAM Volume (2), Number (1). DOI: 10.1897/2005-009.1.

\section{INTRODUCTION}

In various international regulatory frameworks that are concerned with management of chemicals, the identification of persistent $(P)$, bioaccumulating (B), and/or toxic ( $\mathrm{T}$ ) properties is undertaken. The PBT assessment is different from local and regional risk assessment approaches because it seeks to protect ecosystems when and where the risks are more difficult to estimate. The PBT assessment has been developed particularly to take into account the unacceptably high uncertainty in predicting reliable exposure and effect concentrations hampering quantitative risk assessment (EC 2003). Widespread concern exists about the release of persistent organic pollutants that are transported across international boundaries far from their sources and that persist in the environment, bioaccumulate through the food web, and pose a risk to human health and the environment. In some regulatory frameworks, substances that are deemed to be $\mathrm{P}, \mathrm{B}$, and/or $\mathrm{T}$ are not acceptable for registration or are candidates for phasing out; for example, the European Union (EU) Biocides Directive 98/8/EC (Council 1998), the EU Regulation 2004/850 on persistent organic pollutants (Council 2004), the procedure for approval of active substances for ballast water treatment of the International Maritime Organisation (MEPC 2004), the Stockholm Convention on Persistent Organic pollutants, and the United 
Integrated Environmental Assessment and Management: No. 2, pp. 13-21.

Nations (UN) Economic Commission for Europe Long-Range Transboundary Air Pollution (ECE LRTAP) Geneva Convention (UN 1979; UNEP 2001).

In 2002, the Organization for Economic Cooperation and Development (OECD) published the results of a survey on pesticide risk assessment in member countries (OECD 2002a). The primary objective of that survey was to develop a clear understanding of the information relevant to risks associated with PBT properties and ways in which this information is used by member countries. This article presents a detailed evaluation of the regulatory risk assessments of 2 pesticide case studies that were conducted in 2003 by OECD member countries (OECD 2005). This follow-up research had the following objectives:

1. Establish the differences in how member countries identify PB pesticides;

2. Establish the differences in how member countries take $P$ and $B$ into account in the decision-making process;

3. Establish how the assessors' subjectivity influences data interpretation and data selection; and

4. Formulate, taking all information provided into account, recommendations to stimulate harmonization of data selection, hazard and risk assessment, and decision making.

\section{PESTICIDE CASE STUdIES}

The survey of 15 OECD member countries in 2003 included the presentation of 2 case studies involving the consideration for approval of agricultural applications of 2 types of plant protection products to different crops. The 1st substance (substance A) represented a $\mathrm{P}$ and $\mathrm{B}$ substance, which served as a positive control in relation to the risk assessment and decision-making systems implemented by member countries. The 2 nd substance (substance $B$ ) represented a borderline case with respect to $\mathrm{P}$ and $\mathrm{B}$, where data interpretation and data selection strongly influence risk assessment and decision making. Data sets were based on existing substances but were modified to avoid dissemination of confidential information. Fictitious data endpoints were created to provide complete data sets; however, the data relating to ecotoxicology are not presented in this article. A list of questions invited representatives of participating OECD member countries to address essential steps in the assessment of $P$ and $B$ criteria, drawing from their expert knowledge and the underlying documentation provided by their own regulatory programs. The data sets and questions presented in the survey are provided in the Appendix.

\section{Summary of survey results}

The countries that are associated with the EU dominated the survey results. Seven countries were EU member states, 3 joined the EU in 2004, and 2 countries were only members of the OECD. An additional 3 countries included in the survey represented the economic regions of North America and Southeast Asia. The decisions of the 15 participating countries with respect to classification and authorization are depicted in Figure 1 . Some participants did not communicate the exact data selection process that formed the basis for their classification and authorization of the pesticides presented in the 2 case studies. 


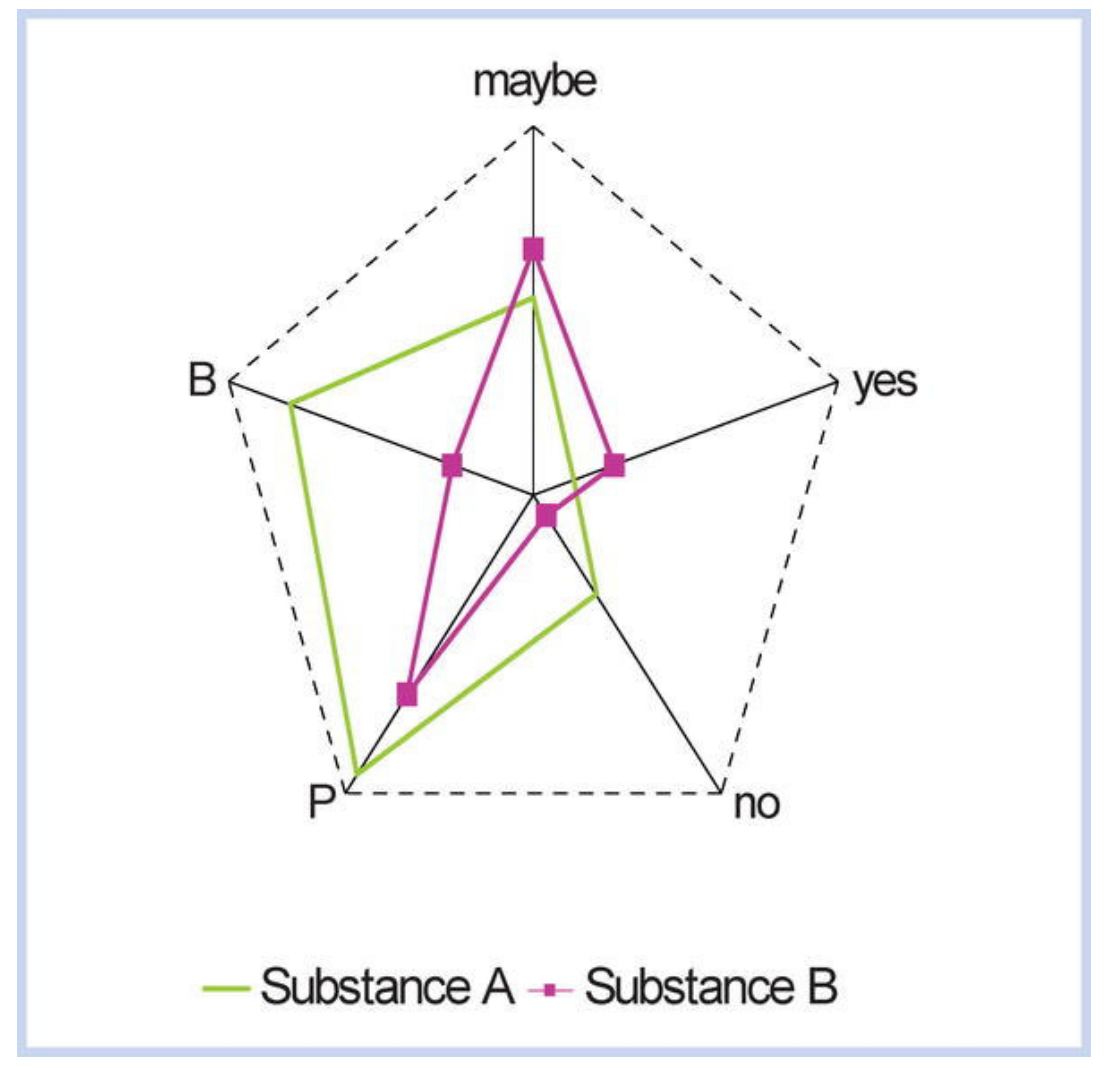

Figure 1 Presentation of the frequencies of classification (persistent $[P]$ and bioaccumulative $[B]$ ) and of the final decision on authorization (yes, no, or maybe) for the reference compound, substance A, and the test compound, substance $B$. The scale is from 0 to 15 (the number of participating countries)

The reference compound, substance A, was determined virtually unanimously as a $P$ and $B$ substance. Two countries did not classify the substance because they do not use any system of qualitative classifications. This indicated that, overall, the scientific opinions were in unison on the nature of the compound and that it is possible to discern $P$ and $B$ substances in different regulatory frameworks. Nevertheless, the assessments resulted in different regulatory decisions among the responding countries (Figure 1). Some countries reached a negative decision based on the properties of substance $A$; other countries, using the same information, supported authorization with some restrictions imposed. This indicated that different regulatory standards are applied by different countries, despite common economic or regulatory frameworks. Several countries concluded that more data were required to reach a decision and that the available endpoints were accompanied by insufficient information on test conditions to properly value the implications. This indicated that the nature of the compound was not disputed but that the scientific standards implemented to evaluate information and the applied risk models differed.

Substance B was determined as a borderline $P$ and $B$ substance and was classified in different ways (Figure 2). Based on the same data set, the scientific opinion on substance B (and its metabolites) diverged. Most countries indicated that further data were required to be able to reach a decision for substance $B$. Again, several countries indicated that the available endpoints were accompanied by insufficient information on test conditions to properly evaluate the implications of approving the substance for agricultural use. For some countries, the 
information needed to reach a risk-based conclusion was insufficient. The risk model applied to address risk seemed to differ, even within EU member countries. For example, the bound-residue data should trigger further investigations under the EU Directive 91/414/EEC, as 2 countries noted in response to survey questions. In the risk assessment, 9 countries addressed this issue, although not all in the same way, whereas 6 other countries did not. Metabolite mA was recognized by 2 countries as a borderline substance with respect to $P$ but was clearly classified as "nonbiodegradable" by 1 country.

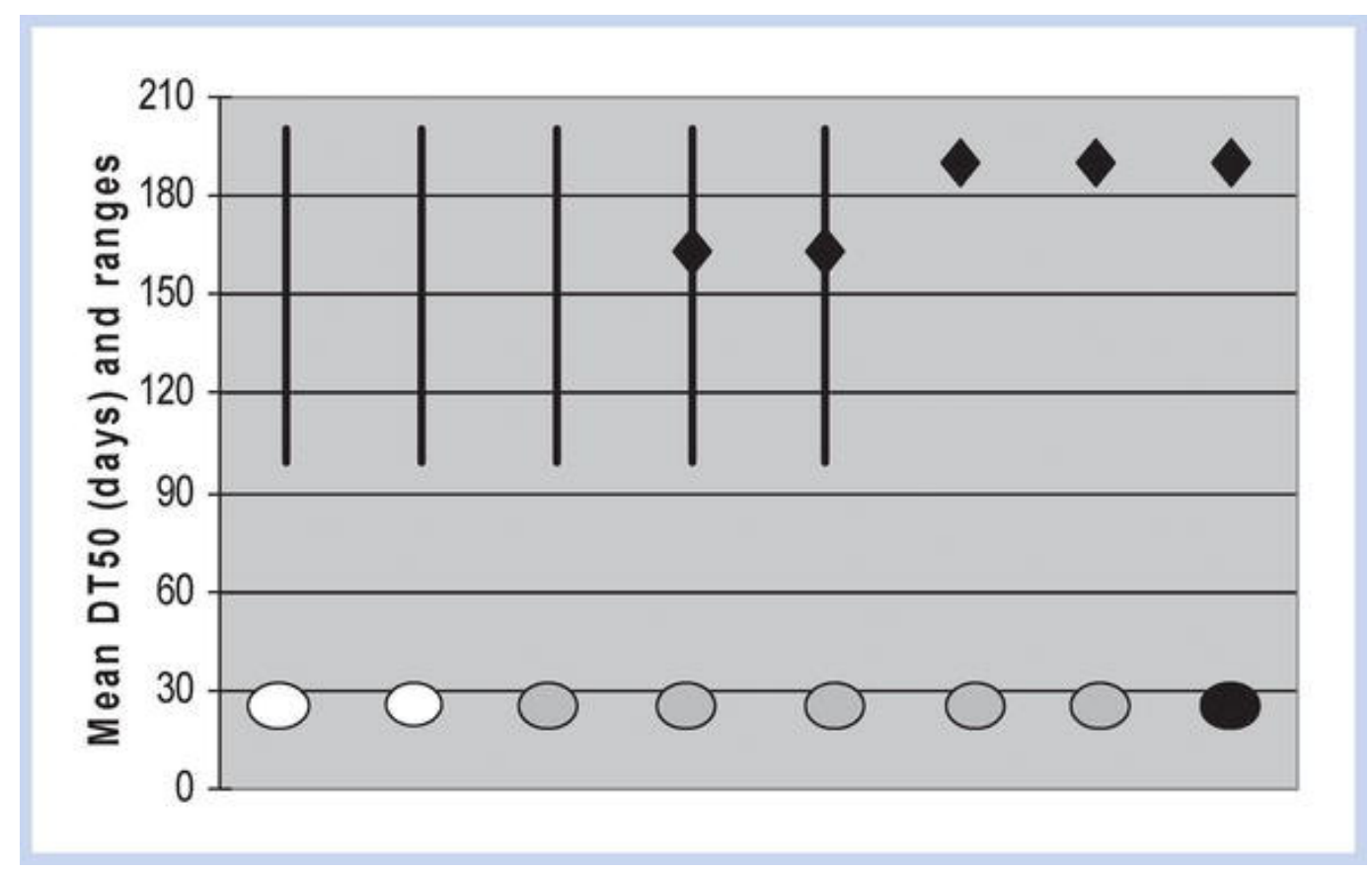

Figure 2 Graphical presentation of mean $(\bullet)$, DT50 values, and ranges in soil used for decision making: White ellipses = approval; grey = undecided; black = no approval

In cases where scientific opinions were the same, the regulatory decisions were different among several countries participating in the survey. Substance B provided a more complex challenge for most countries when compared with substance A because substance B involved 2 metabolites of the parent chemical. The S-isomer was identified by most countries as persistent in soil and sediment, and the R-isomer was identified by most countries as persistent in sediment. Whereas 1 country noted that the half-life times for degradation (DT50 values) of the S-isomer in the soil was acceptable, another country noted that the half-life times were unacceptable. Yet, in those cases in which a P and B classification was reached, the decision-making process apparently differed from that for substance A. In general, $P$ and $B$ classifications were rarely identified as the reason for denying authorization but, instead, triggered a requirement for an advanced risk assessment and sometimes for specific studies.

Figure 1 illustrates that uniform data do not result in uniform scientific opinions, and that uniform scientific opinions on $\mathrm{P}$ and $\mathrm{B}$ properties do not give rise to the same regulatory decisions. Different scientific and regulatory standards appear to apply among the participating countries. It should be noted that only 1 country classified both substances based on an existing classification scheme. Other countries either used the EU Directive 91/414/EEC trigger value for soil 
Integrated Environmental Assessment and Management: No. 2, pp. 13-21.

persistency assessment (which was never intended for classification) or classified the substances without a designated systems.

\section{On which substances are P And B criteria applied?}

In both pesticide case studies, data on formulations, active ingredients, isomers, and metabolites were presented. The questionnaire provided with the case studies asked the 15 participating countries to describe the scope of their risk assessment process in general. In response to the question about which substances are actually assessed on $\mathrm{P}$ and $\mathrm{B}$ properties, 2 countries indicated that they did not have P and B criteria. However, from the case studies it is concluded that the (subsequent) risk assessment approach does not differ substantially among the 15 countries.

In principle, the $\mathrm{P}$ and $\mathrm{B}$ criteria apply to all constituents and metabolites of the technical ingredient, unless-within the EU zone and Japan-the relevancy or activity of metabolites or isomers has been negated. Impurities are not considered. Consumption (tonnage) of the pesticide product, formation rates of the metabolites in an environmental matrix, or application rates are not considered to restrict the scope of the assessment. In the regional legislation of the EU and Japan, however, a formation rate of $10 \%$ (based on parent-compound equivalents) triggers dossier requirements for metabolites. One country has exempted environmental risk assessment for metabolites of all applications with dosages below $5 \mathrm{~g} / \mathrm{ha}$. Some countries consider accumulation in compartments as a criterion because of repeated use over the years or in the region, whereas other countries do not. Whether this specific criterion on repetitive use applies to all compartments or only to soil is unclear, and so are the temporal and spatial boundaries for this criterion.

With regard to the 2 pesticide case studies, it appeared that all countries dealt with the 2 isomers in substance B as separate entities. Only 7 countries referred to the properties of metabolites in the considerations on persistency.

The assessment of inorganic compounds was addressed in a separate question: "Do the standards on $\mathrm{P}$ also apply to inorganic compounds and inorganic metabolites?"

In general, member states responded that they do not apply the $\mathrm{P}$ standards to inorganic compounds. Three countries responded that, for organic substances, $P$ can be estimated (different estimation methods and models are available), whereas for inorganic substances, more expert judgment is needed because estimation models are not available. In 2 countries, $P$ is not considered a meaningful criterion for inorganic compounds (i.e., metals) because they are elements and, therefore, are viewed as P by definition. One country took a more prudent approach and responded that inorganic compounds are not included among the substances defined under the relevant EU legislation. Contrary to these approaches, 2 countries applied cut-off criteria for $P$ to inorganic substances and, in principle, also to relevant inorganic metabolites.

\section{Persistency in environmental compartments}

Data on 3 environmental compartments were supplied for all parent compounds and metabolites in the case studies: soil, water and sediment, and air. In general, persistency in soil received the greatest attention, and persistency in water and sediment and in air was often neglected or considered insignificant. This is probably a reflection of a lack of criteria for water and sediment or for air 
in the uniform principles (UP) applied within the EU (Council 1991). However, some countries apply the criteria from the Stockholm Convention and the Geneva Convention for these compartments. One EU country, however, saw no discrepancy in the UP toward the different compartments and applies the same UP standards to soil, water and sediment, and groundwater.

In those countries where $P$ is classified, the approaches for different compartments differ. Persistency in soil is mostly classified, but in water and sediment much less attention is devoted to this aspect. Persistency in air has been addressed in some assessments. Persistency is generally identified by halflife times in the compartment (DT50), although accumulation potential (which also depends on use patterns such as repetitions and crop rotation) is also considered as a criterion. The numerical values of the criteria differ among compartments and, within a compartment, among countries. The formation of bound residue and mineralization as criteria for $\mathrm{P}$ were addressed by most countries, albeit with different results.

Role of field studies. All 15 countries participating in the survey viewed field studies as highly appreciated and superseding laboratory results with respect to half-life times but generally not with respect to the formation of metabolites. With regard to substance $A$, no data on metabolites in laboratory studies were given to each country for consideration because degradation was negligible. In the field study with substance $A, 11 \%$ of the parent compound was transformed into a metabolite. Six countries noted this, and although field studies were generally not considered to overrule laboratory studies on metabolite formation, in this case a follow-up was considered appropriate.

In general, the field study should be relevant for the conditions of use, and most countries picked a selection of field studies from the data sets. One country did not use field studies because the testing conditions would very rarely be applicable to the national environmental conditions. Violation of persistency limits by field studies usually triggers advanced testing and higher-tier risk assessment and risk mitigation and can be a basis for a negative decision on registration. The required advanced testing usually involves a study on (geo)-accumulation, which addresses the fate of the residue, or field studies on effects, which address the effects of the residue. The UP require a litter bag study at a field DT90 of more than $1 \mathrm{y}$, but this requirement was not noticed by participating countries.

Significance of bound residues. Several opinion and guidance papers have been devoted to the nature and risk of soil-bound residue, in particular, the European Commission Guidance document on P (Craven 2000; EC 2000), the opinion of the Scientific Committee on Plants (SCP) on this guidance (SCP 1999), the European Crop Protection Association (ECPA) opinion on nonextractable residues in soil (ECPA 2000), and recent reviews in the published literature such as Semple at al. (2005). The SCP concluded in its opinion that the fractions of bound residue that are released are small, and any concern over their ecotoxicology or effect on succeeding crops will have been addressed during studies required for the active substance and relevant metabolites. The small fractions released from bound residues, therefore, have no additional significance from a regulatory viewpoint. The SCP believes that there should be no additional study requirements provided that appropriate and satisfactory long-term tests have been carried out (SCP 1999).

The most recent reviews on this issue converge to an opinion that the significance of bound residue is determined by the nature and the bioavailability of the residue. In combination with a low annual turnover rate of soil organic 
matter, a possible future problem is envisaged only for the bound residue of the total chemical burden of the soil (Semple et al. 2005).

The scientific approach to bound residues is ambiguous but not a member state-specific or regional problem. The survey questionnaire asked the 15 participating countries whether there were additional considerations for products that generate large amounts of bound residue. In general, countries responded that the phenomenon of bound residue is addressed generally when formed at levels of more than $70 \%$ of the applied parent compound with 2 options: (1) assessment of fate and behavior by (a) including the amount of bound residue in residue of the active substance during the recalculation of the DT50 for the active substance, or (b) requiring data requirements similar to those following DT50 trigger violations; and (2) assessment of effect by (a) effect of bound residue on sensitive soil fauna, or (b) requiring data similar to those for DT50 trigger violations (litter bag studies).

A UP assessment trigger that covers bound residues and mineralization to carbon dioxide $\left(\mathrm{CO}_{2}\right)$ jointly states that bound residues should form not more than $70 \%$ and $\mathrm{CO}_{2}$ should form less than $5 \%$ at $100 \mathrm{~d}$ in aerobic laboratory soil studies. One EU accession country did not use the 100-d timeframe in assessing bound-residue formation for substances $A$ and $B$ and, hence, did not follow up on this aspect. One country did not consider the criterion, whereas another country assessed the formation of bound residue not only for soil but also for sediment. Two countries referred to definitions of bound residue and suggested that there is a lack of a clear identification in current guidelines of extraction methods by which residues are identified as "bound residues" and are distinguished from residues that can still be extracted with harsh extraction methods. They also suggested that methods to predict the bioavailability of recalcitrant, but still extractable, residues would be useful.

\section{Data selection by assessors}

Crucial in the case studies was the availability of a list of endpoints with limited circumstantial information for the assessors. Selection and manipulation of endpoints by the assessors generated different outcomes under similar sets of criteria. The focal point was the influence of the variation of the information pertaining to substance A and B on the assessment, as well as the ways that selection, standardization of endpoints, and missing information were handled. The responses pertaining to substance $B$ are used here to illustrate key points.

Soil. For substance B, laboratory data were provided to each country for different soil types, dosages, temperatures, and moisture contents in soil. Field data were intended to match different climatic regions. Data selection methods traced back to Mensink et al. (1995) and based on some combination of factors such as temperature, moisture content, organic matter content, dosage, and location of the field study, were likely to influence the identification of 1 or more evaluation endpoints. Data manipulation also was assumed likely to influence the determination of evaluation endpoints and could include correction of endpoints for temperature, use of a range of values for DT50 and DT90, use of classes (after classification), use of a single DT50, use of averages of DT50s, and analyses of the distribution of the results (percentiles).

With regard to substance $B$, the major metabolite $m A$ was not given the same attention as the parent compound by 3 countries (Table 1 ). Three countries considered the "runner-up" metabolite $\mathrm{mC}$ more relevant than metabolite $\mathrm{mA}$ or $\mathrm{mB}$. These results underline that uniform data and uniform evaluation principles 
Integrated Environmental Assessment and Management: No. 2, pp. 13-21.

do not necessarily guarantee uniform assessments among the 15 countries participating in this survey.

Table 1 Appraisal of metabolites $(\mathrm{mA}, \mathrm{mB}, \mathrm{mC})$ and bound residue $(\mathrm{BR})$ in soil of substance $\mathrm{B}^{\mathrm{a}}$

\begin{tabular}{|c|c|c|c|c|c|c|c|c|c|c|c|c|}
\hline \multirow[b]{2}{*}{ Metabolite } & \multicolumn{12}{|c|}{ Country } \\
\hline & A & B & C & D & $\mathrm{E}$ & $\mathrm{F}$ & G & H & 1 & J & K & L \\
\hline $\mathrm{mA}$ & Ack & Fu-P & $\mathrm{NC}^{\mathrm{b}}$ & Fu- $P^{c}$ & Fu- $P^{c}$ & Fu-P & Fu-P & Ack & NC & Fu-P & Fu-P & Fu-P \\
\hline $\mathrm{mB}$ & Ack & Ack $^{\mathrm{c}}$ & $\mathrm{NC}^{\mathrm{b}}$ & Ack & Ack & Fu-P & Ack & Ack & NC & Ack & NC & Ack \\
\hline $\mathrm{mC}$ & Ack & $\mathrm{Ack}^{\mathrm{c}}$ & $N C^{b}$ & Ack & Fu- $-P^{c}$ & Fu-P & Fu-P & Ack $^{c}$ & NC & Ack & NC & Ack \\
\hline BR & Ack & Ack & Fu-P & Ack & Ack & Fu-P & Fu-P & Ack & NC & Fu-P & NC & Fu-P \\
\hline
\end{tabular}

${ }^{\mathrm{a}}$ Ack $=$ acknowledged, but no follow up; Fu-P = follow up on persistency; $\mathrm{NC}=$ not considered.

${ }^{b}$ Because of the unacceptable degradation rate of the parent compound.

${ }^{\mathrm{c}}$ Follow up on groundwater.

The data in Table 2 O=show that different ranges and means for the DT50 of the substance $B$ isomers and $\mathrm{mA}$ were derived using the same data set from laboratory studies. In most cases, the mean values for the R-isomer were within the ranges defined by other countries. Four mean values were below the threshold for further assessment set in the EU UP, and 3 mean values were above the threshold. One country presented 2 mean values for 2 dosages of the Risomer; the mean value at the lower dosage was lower than the UP-trigger of 90 $\mathrm{d}$, and the other mean value was higher than the UP trigger.

Table 2 Mean degradation half-life (DT50) and ranges (in days) for 2 isomers and 1 metabolite $(\mathrm{mA})$ of substance $B$ in laboratory soil ${ }^{\mathrm{a}}$

\begin{tabular}{|c|c|c|c|c|c|c|c|c|c|}
\hline \multirow[t]{2}{*}{ Country } & \multicolumn{3}{|c|}{ R-isomer } & \multicolumn{3}{|c|}{ S-isomer } & \multicolumn{3}{|c|}{$\mathrm{mA}$} \\
\hline & Low & High & Mean & Low & High & Mean & Low & High & Mean \\
\hline A & 30 & 110 & NP & 50 & 240 & NP & 25 & 120 & NP \\
\hline B & 30 & 110 & 76 & 50 & 240 & 162 & 25 & 120 & 77 \\
\hline C & 66 & 110 & 90 & 177 & 208 & 191 & NP & NP & NP \\
\hline D & 60 & 110 & 82 & 110 & 240 & 177 & 25 & 120 & 77 \\
\hline E & 66 & 118 & 92 & 170 & 240 & 194 & 60 & 120 & 90 \\
\hline $\mathrm{F}$ & 66 & 110 & NP & 170 & 240 & NP & 85 & 120 & NP \\
\hline G & 60 & 110 & 82 & 110 & 240 & 176 & 60 & 120 & 90 \\
\hline $\mathrm{H} 1^{\mathrm{b}}$ & NP & NP & 88 & NP & NP & 229 & NP & NP & NP \\
\hline $\mathrm{H} 2^{\mathrm{b}}$ & NP & NP & 104 & NP & NP & 193 & NP & NP & NP \\
\hline 1 & \multicolumn{3}{|c|}{$3 /(n=9)>90$} & \multicolumn{3}{|c|}{$8 /(n=9)>90$} & \multicolumn{3}{|c|}{ NP } \\
\hline$J^{c}$ & \multicolumn{3}{|c|}{$30-100$} & \multicolumn{3}{|c|}{$>100$} & \multicolumn{3}{|c|}{$>100$} \\
\hline K & \multicolumn{6}{|c|}{ all $<1$ y } & \multicolumn{3}{|c|}{ NP } \\
\hline
\end{tabular}

${ }^{\mathrm{a}} \mathrm{NP}=$ not provided

${ }^{\mathrm{b}} \mathrm{H}$ separated the use rate into 2 dosages of $0.1(\mathrm{H} 1)$ and $2.0(\mathrm{H} 2) \mathrm{mg} / \mathrm{kg}$, neither of which matches the proposed use rate of $0.67 \mathrm{lb} / \mathrm{acre}(\sim$ $0.67 \mathrm{mg} / \mathrm{kg}$ ). The $2.0 \mathrm{mg} / \mathrm{kg}$ dosage resulted in a lower DT50 for the R-isomer but a higher DT50 for the S-isomer when compared with the $0.1 \mathrm{mg} / \mathrm{kg}$ dosage.

c $\mathrm{J}$ considered both isomers and metabolites but did not reveal the data selection. From the assigned classes, a DT50 of 30-100 d for the Risomer and a DT50 >100 d for the S-isomer and metabolite A were deduced. It is not clear if ranges or averages were used.

With respect to the substance B S-isomer, the mean values were within the ranges defined by the 11 other countries. The mean DT50 value of $162 \mathrm{~d}$ determined by 1 country was outside the range of the 170 to $240 \mathrm{~d}$ set by another country. Based on these results, one would have to conclude that 2 different substances were presented. Two mean values are below the "very persistent" threshold of $180 \mathrm{~d}$ set for new and existing substances and biocides 
under EU legislation; 4 mean values were above the threshold (EC 2003). One country presented 2 mean values for 2 dosages of the S-isomer. The mean value for the S-isomer at the lower dosage was higher than the DT50 at the higher dosage, as opposed to the R-isomer.

With respect to substance $B$ metabolite $m A$, in most cases, the ranges defined by all countries included the EU UP trigger. An exception was that the mean DT50 value was determined to be $77 \mathrm{~d}$ by 2 countries. This value was outside the range of 85 to $120 \mathrm{~d}$ set by another country, which gives the impression that a different compound was assessed. Four countries did not assess the DT50 of mA. Two mean values were below the EU UP trigger, and 2 mean values were at the trigger value, which means a trigger violation.

Table 3 Field studies in soil: degradation half-lives of DT50 (in days) and DT90 (in months or years) selected for 2 isomers of substance B

\begin{tabular}{|c|c|c|c|c|c|c|c|c|c|c|c|c|}
\hline \multirow[b]{3}{*}{ Country } & \multicolumn{6}{|c|}{ R-isomer } & \multicolumn{6}{|c|}{ S-isomer } \\
\hline & \multicolumn{3}{|c|}{ DT50 } & \multicolumn{3}{|c|}{ DT90 } & \multicolumn{3}{|c|}{ DT50 } & \multicolumn{3}{|c|}{ DT90 } \\
\hline & Low & High & Mean & Low & High & Mean & Low & High & Mean & Low & High & Mean \\
\hline A & 12 & 100 & $N P^{a}$ & $2 m$ & $1 y$ & NP & 100 & 200 & NP & $1 y$ & $2 y$ & NP \\
\hline B & 12 & 100 & 65 & $2 m$ & $1 y$ & NP & 100 & 200 & 163 & $1 y$ & $2 y$ & NP \\
\hline C & 12 & 100 & 67 & NP & NP & NP & NP & NP & 190 & NP & NP & NP \\
\hline D & 12 & 100 & NP & NP & NP & NP & 100 & 200 & NP & NP & NP & NP \\
\hline$E$ & 12 & 100 & 67 & $2 m$ & $1 y$ & NP & NP & NP & 190 & & $2 y$ & \\
\hline $\mathrm{F}$ & 25 & 100 & 60 & NP & NP & $9 m$ & 100 & 200 & 163 & & $20 \mathrm{~m}$ & \\
\hline G & 12 & 98 & 59 & $2 m$ & $1 y$ & NP & NP & NP & 190 & & $2 y$ & \\
\hline H & 40 & 70 & 65 & NP & NP & NP & 100 & 200 & NP & & $1 \mathrm{y}, 2 \mathrm{y}$ & \\
\hline I & \multicolumn{3}{|c|}{$2 /(n=9)>90$} & \multicolumn{3}{|c|}{ NP } & \multicolumn{3}{|c|}{$3>90,2>180$} & \multicolumn{3}{|c|}{ NP } \\
\hline K & \multicolumn{12}{|c|}{ Some DT50 > $100 \mathrm{~d}$} \\
\hline
\end{tabular}

${ }^{\mathrm{a}} \mathrm{NP}=$ not provided

The results of the assessment of field data are summarized in Table 3. Five countries established the wider range of field DT50 values for the R-isomer (12$100 \mathrm{~d})$, although 1 country decided on the narrower range (40-70 d). The mean DT50s were close: 59 to $67 \mathrm{~d}$, but the mean DT50 in 1 country was found to be $43 \%$ higher ( $86 \mathrm{~d}$ ). DT90 values as decision-making endpoints were viewed by most countries as less favorable data. For the S-isomer, 4 countries established comparative ranges (100-200 d), 2 countries defined a mean DT50 of $163 \mathrm{~d}$, and 3 countries defined a single DT50 of $190 \mathrm{~d}$. One country noted that, in all cases, the DT50 was >90 d, whereas all other countries noted the DT50 was >180 d. Four countries noted DT90 values, with a preference for the higher findings ( $2 \mathrm{y}$ ).

The final decision on authorization was generally based on the field DT50 for the substance B S-isomer. The results in Figure 2 show the nearly identical assessments of chemical properties by the 15 participating countries. However, uniformity in the scientific appraisal does not necessarily result in identical decisions because of different regulations. In Figure 2, the initial 5 identical ranges resulted in 2 different opinions: 2 authorizations and 3 requests for more information. The last 3 single values resulted in 2 opinions: 2 requests for more information and 1 refusal to grant authorization of substance $B$ for agricultural use. 
Integrated Environmental Assessment and Management: No. 2, pp. 13-21.

Bioaccumulation. With respect to B data requirements and study interpretation, almost no harmonization existed in the use of data on degradation, clearance rates, and exposure patterns.

With regard to substance $A$, bioconcentration factors (BCFs) for 3 different organisms: 1 lotic fish (Lepomis macrochirus), 1 sediment dwelling fish (Anguilla anguilla), and 1 bivalve fish (Mytilus edulis) were given based on wet weight of the whole organism (ww/wo). Additional information was given for $L$. macrochirus on clearance rates and elimination, and for $A$. anguilla, the organic carbon content of the used sediment was presented.

The $B$ assessment was not performed in 1 country because of the lack of an established protocol. The other 14 countries made classifications for the substance (substance $A$ is bioaccumulating) or for combinations of specific taxa and substances (substance $A$ is highly bioaccumulating in shellfish). When countries saw the need for a distinction between compartments or species, generally only the $\mathrm{BCF}_{\mathrm{ww} / \mathrm{wo}}$ for the aquatic compartment and $\mathrm{BCF}_{\text {fat tissue }}$ for the vertebrates were discerned. Several EU countries did not consider the $\mathrm{BCF}_{\text {fat tissue }}$. The criteria applied to B (e.g., BCF and half-life time for clearance, CT50) were the same for all test species.

Overall, the subsequent conclusions on acceptability based on B were either based on BCF endpoints, often in combination with persistency endpoints; endpoints together with information on log $K_{\text {ow }}$, clearance rates, and use patterns; or combinations of environmental risks (including secondary poisoning) related to the mode of application of the plant protection product.

Whereas for 1 country the relative short-term exposure of a single application compared with repeated applications was an argument to accept the BCF properties for a single application, for another country, the prolonged exposure of a single application of a $\mathrm{P}$ compound was an argument not to approve its use. One country used a standard for the clearance rate if the BCF was between 100 and 1,000 , regardless of repetitive use. Another country always used clearance rates together with BCF for classification. Other countries used a case-by-case approach. No further attention was paid to the relationship between the clearance rates, body size, lipid content, or BCF.

For some countries, a B classification meant no approval. For other countries, $\mathrm{BCF}$ does not trigger new investigations, mostly because secondary poisoning is routinely assessed. The EU UP trigger examination of risk of secondary poisoning, which typically involves consideration of birds consuming fish and earthworms. That was considered sufficient by 1 country at relatively low levels of $B$, but at higher levels (approaching the UN Environment Programme, UNEP, criteria) further factors would preferably be added to the risk assessment, for instance, assessing the risk from bioconcentration in invertebrates.

Interestingly, contamination of agricultural meat products was mentioned by only 1 country. In addition, another EU member state noted that the type of study required in the EU to address the chronic risk to fish depends on the BCF. For example, a fish early life-cycle study is required by the UP where the BCF is between 100 and 1,000.

Overall, in both pesticide case studies, environmental risk assessments in relation to BCF were performed by considering the aquatic ecosystem, the terrestrial ecosystem, secondary poisoning of predators, risk for biomagnification 
in aquatic and terrestrial food chains, and/or fodder residues and livestock product (meat) contamination.

BCF was further assessed by nearly all countries based on consideration of the proposed use patterns and reported clearance rate. For some countries, the endpoint itself was decisive; whereas, for other countries, the interval between repeat applications, clearance time, or degradation rate was most important. Additionally, organ-specific bioaccumulation and uncompleted elimination was taken into account on a case-by-case basis.

One aspect that was not analyzed in the case studies was the difference between BCF based on measurements ( $\mathrm{C}_{\text {oranism }} / \mathrm{C}_{\text {water }}$ ) and $\mathrm{BCF}$ based on calculated uptake-elimination kinetics $\left(k_{1} / k_{2}\right)$. The numerical results may differ strongly, depending on equilibrium kinetics and test designs.

On the issue of biomagnification, 2 lines of reasoning were generally followed by the 15 countries participating in the survey. One line of reasoning suggested that secondary poisoning modeling would address relevant risks. The 2 nd line of reasoning suggested that the uncertainty in these approaches made it preferable for an early stage cut-off (e.g., BCF greater than 5,000 and $\mathrm{BCF}_{\text {fat tissue }}$ greater than 1). Neither line of reasoning was, however, harmonized, and the $\mathrm{BCF}_{\text {fat }}$ tissue was not applied in practice. Consensus on the definition of the $\mathrm{BCF}_{\text {fat tissue }}$ is desirable. The questions that remain unanswered are how this parameter should be determined and what role it should play in the risk assessment process.

Table 4 Guidance and protocols used by 15 countries to evaluate the persistence and bioaccumulation potential of substances $A$ and $B$

The European Union uniform principles (Annex VI to 91/414/EEC) (Council 1991).

United Nations (UN) Economic Commission for Europe Long-Range Transboundary Air Pollution (ECE LRTAP), Executive Body Decision 1998/2 (UN 1979).

National legislation and/or policy criteria documents.

The following sources were identified as guidance on study evaluation:

SETAC procedures for assessing the environmental fate and ecotoxicity of pesticides (Lynch 1995, also mentioned in the EU Directive 91/414/EEC),

The RIVM manual (Mensink et al. 1995) RIVM report 679101022.

The following sources were identified as guidance on risk assessment:

The European Union (DG SANCO) guidance documents (EC 2000; EC 2002; ECCO 2002).

SETAC procedures for assessing the environmental fate and ecotoxicity of pesticides (Lynch 1995).

The RIVM Manual (Mensink et al. 1995)

The EPPO Risk Assessment (EPPO 1993)

Report of the Effects of Plant Protection Products on Functional Endpoints in Soil (EPFES) workshop in Lisbon, April 2002 (Römbke et al. 2003)

The European Chemicals Bureau technical guidance document (TGD) (EC 2003)

The EU Uniform Principles (Annex VI to EU Directive 91/414/EEC)

Code of Federal Regulations, Title 40, part 158, pesticide assessment guidelines subdivisions E, J, L, N (USA)

Data requirements for supporting registration of pesticides (Notification No.12-Nousan-8147 24 November 2000), Japan. 
Integrated Environmental Assessment and Management: No. 2, pp. 13-21.

\section{Available guidance and protocols used by participating countries}

Asked to reference specific guidances and protocols, countries responded that their evaluation of substances $A$ and $B$ relied on the list of documents shown in Table 4. Differences in data selection or decision making may be the result of different approaches or of different interpretation of a guidance. The use of harmonized guidances and protocols for summarizing studies, data selection and handling, and risk assessment will contribute to a consistent and uniform decision-making process.

\section{Discussion}

The influence of the evaluator subjectivity on the interpretation of raw data needed for exposure modeling has already been demonstrated by Brown et al. (1996), Thiessen et al. (1997), Boesten (2000), and Tiktak (2000). These and other researchers generally regard the interpretation of raw data as a process typically suited to predetermined model capabilities, with the result that the individual data selections create a greater bias than the different models would have done on 1 set of endpoints. Selection of published literature for suitable endpoints is also very complicated, and may result in erroneous data, as reported by Pontolillo and Eganhouse (2001).

However, because in the EU, member states will have to depend for national registration on a common list of endpoints for substances listed in Annex I of Directive 91/414/EEC (EC 2002) and because the Food and Agriculture Organisation investigates the use of complete assessments and lists of endpoints in developing countries, it was decided to provide such a list of endpoints (OECD 2002b; ECCO 2003). It should be noted that within the EU, there is already an intensive exchange of pesticide data and risk assessments between member states and EU scientific bodies, which has given rise to several guidance documents on risk assessment. The present study has highlighted that the stage before the risk assessment, in other words, the selection of endpoints to be used in models and assessments, could benefit from further guidance and harmonization.

The case studies generated a vast amount of information on decision making, risk assessment, risk classification, and data treatment. In general, the observed differences between OECD member states (and even among EU member states) gives some cause for concern. Clearly, different approaches exist for the classification of substances and the subsequent use of $P, B$, and $T$ information in decision making. Registration frameworks in the 15 different countries identify $P$ and $B$ as important aspects of pesticides that, in general, merit special consideration. The registration frameworks can even decide on $P$ and $B$ as independent qualities, as noted by 5 out of 15 participating countries, for which cutoff values apply for persistency in soil and for bioaccumulation. Three of these countries are EU member states and have imposed national legislation or policy making for higher-tier assessments, supplementary to the implementation of Directive 91/414/EEC. One additional EU member country indicated that it would apply the criteria of the Stockholm Convention when ratified. Apparently, some countries believe that currently applied assessment strategies are not sufficient to address the possible implications of bioaccumulation and biomagnification.

Further, most countries believe that uncertainty in higher-tier risk assessments and the merits of trigger values also should be considered in $\mathrm{P}, \mathrm{B}$, and $T$ evaluations. The legislation underlying registration demands risk assessment but does not specify when effects are deemed unacceptable. It appears that for 
Integrated Environmental Assessment and Management: No. 2, pp. 13-21.

some, properties of a higher-tiered risk assessment do not increase confidence in demonstrating that unacceptable effects are absent. Applying trigger values on substance properties or on exposure concentrations is suggested as an alternative.

However, based on the substance $A$ and $B$ pesticide case study results, it appears that there are no harmonized agreements on classification of $\mathrm{P}, \mathrm{B}$, and $\mathrm{T}$. Unanswered questions include the need for clarification of what is actually classified, what information is needed to do so, and under what standard conditions data should be judged. Classification is often done for each environmental compartment (i.e., soil, water, and air); in some cases, chemical classification is based on compound-matrix combinations and different standards. Some countries labeled either substance $A$ or $B$ as a $P$ on the basis of the properties of the active ingredient, its isomers, or its metabolites. Other countries refrained from this approach and classified the particular isomer as $\mathrm{P}$, some even classified the isomer in conjunction with a specific compartment or a (presumably representative) compartment property (e.g., soil type or $\mathrm{pH}$ ). Bound-residue formation and mineralization were not always addressed as parameters for persistency. Also the numerical values for classifications differ. Some countries applied the UP triggers from EU Directive 91/414/EEC (EC 2002), some used additional international agreements published by international bodies, and other countries did not use fixed triggers.

The EU Forum for the Coordination of the Use of Models (FOCUS) is finalizing a guidance document on degradation kinetics that may provide further technical guidance. The objective of the FOCUS work group addressing degradation kinetics is to prepare a guidance document for calculating degradation rates of parents and metabolites from laboratory and field studies, including the application of kinetic endpoints in regulatory assessments (FOCUS 2004). This guidance shows great promise for harmonizing the technical aspects of risk assessment.

Additional training, peer review, and an exchange of experiences are effective instruments in further achieving a high level of harmonization while providing a basis for a further elaboration of risk methodology and rules for decision making. Despite all the guidance documents on data handling and data interpretation, risk assessors are the people who finally make the assessment. Qualified experts on environmental chemistry and ecotoxicology are indispensable assets in the product authorization framework, not only faor pesticides but also for other chemicals (see e.g., Montforts and De Knecht 2002). Surveys to monitor future harmonization should, therefore, be encouraged by the OECD or the UN.

To achieve full harmonization clearly involves regulatory choices. It will not suffice to provide further guidance on technical matters only. At this time, the risk assessment of widely used products in a continent or climatic region is outside the scope of the proposed risk assessment strategies for national registration. The Stockholm Convention on Persistent Organic Pollutants became legally binding on 17 May 2004 and will provide a basis for global harmonization of decision making on the identification of $\mathrm{P}$ and $\mathrm{B}$ for pesticides currently in use and pesticides proposed for agricultural use in the future. 


\section{References}

Boesten JJTI. 2000. Modeller subjectivity in estimating pesticide parameters for leaching model using the same laboratory data set. Agric Water Manag. 44:389-409.

Brown CD, Baer U, Günther P, Trevisan M, Walker A. 1996. Ring test with the models LEACHP, PRZM2, and VARLEACH: Variability between model users in prediction of pesticide leaching using a standard data set. Pestic Sci. 47:249-258.

[Council] The Council of the European Union. 1991. . Council Directive 91/414/EEC of 15 July 1991 concerning the placing of plant protection products on the market.

[Council] The Council of the European Union. 1998. . Council Directive 98/8/EC of the European Parliament and of the Council of 16 February 1998 concerning the placing of biocidal products on the market.

[Council] The Council of the European Union. 2004. . Regulation (EC) 850/2004 of the European Parliament and of the Council of 29 April 2004 on persistent organic pollutants and amending Directive 79/117/EEC.

Craven A. 2000. Bound residues of organic compounds in the soil: The significance of pesticide persistence in soil and water-A European regulatory view. Environ Pollut. 108:15-18.

[EC] The European Commission Directorate General. 2000. Guidance document on persistence in soil. Brussels, Belgium: EC DG for Agriculture, DG VI B II.1-9188/VI/97-rev.8 of 12.7.2000.

[EC] The European Commission Directorate General. 2002. Guidance document on terrestrial ecotoxicology under Council Directive 91/414/EEC. Brussels, Belgium: DG Health and Consumer Affairs. SANCO/10329/2002-rev.2 final.

[EC] The European Commission Directorate General. 2003. Technical guidance document in support of Commission Directive 93/67/EEC on risk assessment for new notified substances, Commission Regulation (EC) 1488/94 on risk assessment for existing substances, and Directive 98/8/EC concerning the placing of biocidal products on the market. Gare (LU). Office for Official Publications of the European Communities.

ECCO. 2002. Guidance document on aquatic ecotoxicology. DG Health and Consumer Affairs. SANCO/3268/2001-rev.4 (final) 17 October 2002.

ECCO. 2003. Draft guidance document for preparation of the "List of End Points" for chemical active substances. Developed within the framework of the European Commission's peer review programme on possible inclusion of active substances of plant protection products in Annex I of Council Directive 91/414/EEC. Braunschweig (DE): Biologische Bundesanstalt fuer Land- und Forstwirtschaft. 4878/ECCO/BBA/99-rev.6.

[ECPA] European Crop Protection Association. 2000. ECPA position paper on soil non-extractable residues. Brussels, Belgium. D/00/SuM/5277.

[EPPO] European and Mediterranean Plant Protection Organization. 1993. Decision-making scheme for the environmental risk assessment of plant protection products. EPPO Bulletin. 23:1-165.

[FOCUS] Forum for the Coordination of the Use of Models. 2004. Guidance document on estimating persistence and degradation kinetics from environmental fate studies in EU registration. Brussels, Belgium. Draft 29/2/04.

Lynch MR. 1995. Procedures for assessing the environmental fate and toxicity of pesticides. Brussels (BE). Society for Environmental Toxicology and Chemistry-Europe.

Mensink BJWG, Montforts MHMM, Wijkhuizen-Maslankiewicz L, Tibosch H, Linders JBHJ. 1995. Manual for summarising and evaluating the environmental aspects of pesticides. Bilthoven (NL). RIVM. RIVM report 679101022

[MEPC] Marine Environment Protection Committee. 2004. Procedure for approval of ballast water management systems that make use of active substances. London (UK). The International Maritime Organisation. Draft October 2004.

Montforts MHMM, De Knecht JA. 2002. European medicines and feed additives regulation are not in compliance with environmental legislation and policy. Toxicol Let. 131:125-136. 
Integrated Environmental Assessment and Management: No. 2, pp. 13-21.

[OECD] Organization for Economic Cooperation and Development. 2002a. Persistent, bioaccumulative and toxic pesticides in OECD member countries. Paris, France. ENV/JM/MONO(2002)22.

[OECD] Organization for Economic Cooperation and Development. 2002b. Report of the OECD Workshop on sharing the work of agricultural pesticide reviews; 2001 February 12-February 14; Brussels, Belgium. Paris, France. OECD Series on Pesticides No. 13.

[OECD] Organisation for Economic Co-operation and Development. 2005. The assessment of persistency and bioaccumulation in the pesticide registration frameworks within the OECD region. Paris, France. OECD Series on Pesticides No. 25.

Pontolillo J, Eganhouse RP. 2001. The search for reliable aqueous solubility $\left(\mathrm{S}_{\mathrm{w}}\right)$ and octanol-water partition coefficient $\left(\mathrm{K}_{\mathrm{ow}}\right)$ data for hydrophobic organic compounds: DDT and DDE as a case study. Reston (VA). US Geological Survey. Water-Resources Investigation Report 01-4201.

Römbke J, Heimbach F, Hoy S, Kula C, Scott-Fordsmand J, Sousa P, Stephenson G, Weeks J. 2003. Effects of plant protection products on functional endpoints in soil (EPFES). In:. Society for Environmental Toxicology and Chemistry-Europe (SETAC-Europe) 15th Annual Meeting; 2002 April 24-April 26; Lisbon, Spain. Pensacola (FL), USA.

[SCP] Scientific Committee on Plants. 1999. Opinion of the Scientific Committee on Plants on the draft guidance document on persistence in soil (DG VI-9188/VI/97-Rev.5 of 20.12.1998). Brussels, Belgium.

Semple KT, Jones KC, Craven A. 2005. Introductory remarks to the special issue on bound residues. Environ Pollut. 133:1-2.

Thiessen KM, Hoffman FO, Tantavaara A, Hossain S. 1997. Environmental models undergo international test: The science and art of exposure assessment modeling were tested using real-world data from the Chernobyl accident. Environ Sci Technol. 31:358-363.

Tiktak A. 2000. Application of nine pesticide leaching models to the Vredepeel dataset: Pesticide fate. Ag Water Manag. 44:119-134.

[UN] United Nations. 1979. Convention on long-range transboundary air pollution. Geneva, Switzerland.

[UNEP] United Nations Environment Programme. 2001. Stockholm convention on persistent organic pollutants (POPs). Stockholm, Switzerland. 